\title{
Ephedrine production from suspension cultures of Ephedra alata L. callus
}

\author{
Ghada A. Hegazi *, Heba E. Ghareb, Mahdia F. Gabr \\ Department of Genetic Resources, Desert Research Center, Cairo, Egypt
}

\begin{abstract}
Ephedra alata is an important Egyptian medicinal plant with enormous applications in pharmaceutical industry. Shake-flask suspension cultures of $E$. alata were established from internodal segment-derived callus. The suspension cultures were treated with two biotic elicitors, namely Aspergillus niger and yeast extract, to enhance the synthesis of ephedrine - the bioactive constituent of $E$. alata. Ephedrine was quantified using the high performance liquid chromatography technique. Ephedrine concentration was not directly related to biomass production. Aspergillus niger and yeast extract enhanced the production of ephedrine by 2.5- to 7 -fold after different durations of incubation as compared to ephedrine content in the mother plant. Treatment with the fungal elicitor A. niger extract induced the maximum accumulation of ephedrine at the concentration of $1.67 \%$; it also increased ephedrine biosynthesis by 7 -fold in 24-day-old culture as compared to the ephedrine content in the mother plant and caused higher ephedrine biosynthesis than that in the control treatment without elicitors. The present protocol could be applicable for the large-scale production of ephedrine from $E$. alata.
\end{abstract}

Key words: shake-flask culture, in vitro, alkaloid, biotic elicitor, Aspergillus niger, yeast extract

\section{Introduction}

Ephedra alata L. is an Egyptian natural plant species found mainly in Sinai desert and Eastern Mediterranean coastal region (Boulos, 2009). It is a pharmaceutically important plant, which belongs to the Ephedraceae family of gymnosperms and is known to have a number of medicinal properties. Ephedra alata shows antimicrobial, antioxidant, and hypoglycemic activities (Soltan and Zaki, 2009; Parsaeimehr et al., 2010; Chebouat et al., 2014; AlSnafi, 2017). In general, plants in the genus Ephedra have been used in traditional medicine to treat allergy, bronchial asthma, chills, cold, cough, edema, fever, flu, nasal congestion, and headache (Parsaeimehr et al., 2010).

Phytochemical analysis of $E$. alata indicated the presence of tannins, cardiac glycosides, alkaloids, phenolics, reducing sugars, and flavonoids (Jaradat et al., 2015). Additionally, Ephedra species contain alkaloids such as ephedrine, pseudoephedrine, norephedrine, norpseudoephedrine, methylephedrine, methylpseudoephedrine, ephedroxane, and ephedradine A-D. Phenolic compounds including chlorogenic acid, rutin, catechin, quercetin, and coumaric acid and various flavonoids have also been isolated from $E$. alata. The total amount of alkaloids isolated from $E$. alata aerial parts was $0.2-0.22 \%$ (Al-khateeb et al., 2014), and the amount of ephedrine and pseudoephedrine was $0.05-0.19 \%$ and $>0.5 \%$, respectively (Al-Snafi, 2017).

Ephedrine is a naturally occurring alkaloid in different species of Ephedra. It is used as a drug and has structure and activity similar to those of adrenaline, which raises blood pressure, heart rate, and respiratory capacity (Limberger et al., 2013). Ephedrine produces several pharmacological effects such as cardiovascular effect (it increases the arterial pressure by peripheral vasoconstriction and cardiac stimulation), bronchodilatation, nasal decongestion, mydriasis, nocturnal enuresis, spinal anesthesia, appetite suppressant and weight loss, cytotoxic effects, and many other (Al-Snafi, 2017).

\footnotetext{
* Corresponding author: Department of Genetic Resources, Desert Research Center, Mathaf El-Matareya, 11753, Cairo, Egypt; e-mail: ghada.hegazi1211@gmail.com
} 
Most of the ephedrine produced today for medical use is obtained by chemical synthesis, because the process of extracting and isolating from the plant is difficult and economically costly (Limberger et al., 2013). Therefore, it is necessary to find an effective, practical, and economically feasible method to provide a continuous, natural, and pure source of ephedrine in large quantities as an alternative to the synthesized one that causes negative side effects. Therefore, attention should be given to isolate natural compounds instead of producing synthetic ones (Khan et al., 2017).

Plant cell and tissue cultures have been used for the production of various valuable phytochemicals, including important alkaloids. They provide a pure continuous source of secondary metabolites independent of geographical or climatic conditions and within a short time period as compared to the extraction from wild plants (Gonçalves and Romano, 2018). In vitro culture systems act as an alternative method for the production of secondary metabolites, thereby conserving the natural sources (Ahmad et al., 2013). In addition to enabling the cultivation of many plants with products of high medicinal value, plant cell cultures are considered as a promising source for the sustainable production of pharmaceutically valuable secondary metabolites. However, the commercialization of the cell suspension-mediated synthesis of secondary metabolites for industrial production is often limited by low yield (Yue et al., 2016).

The accumulation of secondary metabolites in plants is a part of their defense mechanism against pathogen attack and also play important roles in the interaction of the plant with its environment (Taha et al., 2009; Ramirez-Estrada et al., 2016). The defense of the plant is triggered and activated by elicitors, which are signal compounds of plant defense responses. Hence, the treatment of plant cells with elicitors has been one of the most useful strategies to effectively enhance secondary metabolite production quantitively and qualitatively (Verma et al., 2016 and Narayani and Srivastava, 2017).

Elicitors are compounds of biological or nonbiological origin. Abiotic elicitors have nonbiological origin and are grouped into physical, chemical, and hormonal factors. Biotic elicitors have biological origin and are derived from the pathogen or from the plant itself (Shakya et al., 2017). The mechanism of elicitation is complex and depends on various factors, including specificity of elicitor, duration of treatment, cell or tissue growth phase, elicitor concentration, medium composition, light, etc. However, it is well known that elicitors activate signaling pathways and transcription factors, which leads to the production of secondary metabolites in plants (Schluttenhofer and Yuan, 2015). Aspergillus niger and yeast extract are among the most effective elicitors in enhancing the production of valuable secondary metabolites in vitro, especially alkaloids (Roat and Ramawat, 2009; Taha et al., 2009; Udomsuk et al., 2011; Mendhulkar and Vakil, 2013; Pirian and Piri, 2013; Vakil and Mendhulkar, 2013; Ahmed and Baig, 2014; Gadzovska et al., 2015; Nadeem et al., 2018). Therefore, in the present study, two biotic elicitors, namely $A$. niger and yeast extract, were screened for the enhancement of ephedrine accumulation in suspension cultures of $E$. alata. This study is the completion of the previous research study on the production of callus from $E$. alata and the extraction of ephedrine (Hegazi and El-Lamey, 2011). To the best of our knowledge, this is the second report on the in vitro production of ephedrine and the first one on the induction of suspension culture of $E$. alata.

\section{Materials and methods}

\section{Induction of callus cultures}

Ephedra alata terminal actively growing shoots were collected from El-Zohria Botanical Garden in Cairo. Plant specimens were identified by Dr. Omran Ghaly, Head of Plant Taxonomy Unit, Desert Research Center, Egypt. Voucher Herbarium specimens were given the number CAIH-1007-R and were deposited in the Herbarium of Desert Research Center (CAIH). They were washed under running tap water and a detergent for $5 \mathrm{~min}$. Then, they were sterilized for $30 \mathrm{~min}$ in $20 \%\left(\mathrm{vv}^{-1}\right)$ commercial bleach solution (Clorox containing $1 \%$ sodium hypochlorite) and rinsed five times with sterile distilled water. The wound terminal ends were trimmed, and $1.0 \mathrm{~cm}$ internodal segments were used as explants.

For the induction of callus, internodal segments were cultured on ready-made Murashige and Skoog basal medium (MS; Murashige and Skoog, 1962; Duchefa, Haarlem, the Netherlands) supplemented with $3 \%\left(\mathrm{wv}^{-1}\right)$ sucrose, $4.52 \mu \mathrm{M}$ of 2,4-dichlorophenoxy acetic acid (2,4-D), and 4.6 $\mu \mathrm{M}$ kinetin (Kn) (Sigma Cell Culture, min. $90 \%$, St. Louis, USA). The $\mathrm{pH}$ of the medium was adjusted to $5.7-5.8$ using $0.1 \mathrm{~N} \mathrm{HCl}$ or $\mathrm{NaOH}$ and solidified with $0.25 \%\left(\mathrm{wv}^{-1}\right)$ phytagel (Duchefa), before 
autoclaving at a pressure of $1.06 \mathrm{~kg} \cdot \mathrm{cm}^{-2}$ and $121^{\circ} \mathrm{C}$ for $15 \mathrm{~min}$. Subcultures were continued every 60 days for five times, and the callus was incubated under fluorescent light (2500-3000 lux) at $25 \pm 2{ }^{\circ} \mathrm{C}$ with a 16 -h photoperiod (Hegazi and El-Lamey, 2011).

\section{Establishment of suspension cultures}

\section{Shake-flask culture}

Suspension cultures were established using $3.0 \mathrm{~g}$ of fresh friable callus, obtained from the internodal segments, in $100 \mathrm{ml}$ Erlenmeyer flasks containing $30 \mathrm{ml}$ of the liquid-optimized MS medium supplemented with $4.52 \mu \mathrm{M}$ of $2,4-\mathrm{D}$ and $4.6 \mu \mathrm{M}$ of $\mathrm{Kn}$, in addition to the different treatments of two biotic elicitors without phytagel. The $\mathrm{pH}$ of the medium was adjusted to $5.7-5.8$ before autoclaving, as mentioned previously. The suspension cultures of $E$. alata were grown in Erlenmeyer flasks as mentioned above, and the elicitors were added on the $14^{\text {th }}$ day to the cultures during the stationary phase of growth.

\section{Elicitation}

Preparation of $A$. niger extract

The fungus $A$. niger was obtained from the Department of Botany and Microbiology, Al-Azhar University, Cairo, Egypt. It was grown in potato dextrose broth in a shake flask $(1000 \mathrm{ml})$ with $200 \mathrm{ml}$ medium on a rotary shaker $(120 \mathrm{rpm})$ at room temperature. After 3 weeks, the fungal cultures were harvested. They were autoclaved along with the media, and the fungal mycelial mat was then removed carefully, washed with distilled water, and left to dry in hot air oven at $40^{\circ} \mathrm{C}$ until a constant dry weight was obtained. The dried mycelial mat was ground into powder using a mortar and a pestle. Five grams of the dried mycelial powder was added to $500 \mathrm{ml}$ of acidified distilled water ( $\mathrm{pH} 2$ ) and boiled for $40 \mathrm{~min}$. Then, the culture was filtered, and the $\mathrm{pH}$ of the filtrate was adjusted to 5.0 using $1.0 \mathrm{~N} \mathrm{NaOH}$. The volume was then adjusted to $500 \mathrm{ml}$ with distilled water. This solution was autoclaved at $1.06 \mathrm{~kg} \cdot \mathrm{cm}^{-2}$ and $121^{\circ} \mathrm{C}$ for 15 min (Vakil and Mendhulkar, 2013).

\section{Preparation of yeast extract}

Yeast extract was prepared according to the method of Peltonen et al. (1997). One gram of yeast powder (Sigma-Aldrich, St. Louis, USA) was dissolved in $100 \mathrm{ml}$ of distilled water, autoclaved at $1.06 \mathrm{~kg} \cdot \mathrm{cm}^{-2}$ and $121^{\circ} \mathrm{C}$ for $15 \mathrm{~min}$, before being added to the culture medium at different concentrations.

\section{Application of elicitors}

Aspergillus niger extract at concentrations of 1.67\%, $3.33 \%$, and $5 \%$ and yeast extract at concentrations of $5 \%$, $10 \%$, and $15 \%$ were added to the culture medium in order to increase the yield of ephedrine. The control treatment was made without elicitors. Flasks were closed with cotton plugs, and two layers of aluminum foil were loosely placed on the top to leave sufficient space for gas exchange. The flasks were incubated on a rotary shaker (DAIHAN Scientific, Korea) at the speed of $100 \mathrm{rpm}$ at $25 \pm 2{ }^{\circ} \mathrm{C}$ under 16 -h photoperiod in the growth room. Cultures were collected at each growth stage up to the $24^{\text {th }}$ day of incubation at 6-day intervals. They were filtered using a filter paper to remove excess water, and fresh weight was determined. Dry weight was determined after drying the cultures in an oven at $60^{\circ} \mathrm{C}$ until a constant weight was obtained. Ephedrine concentration was determined in the dry matter. The yield of ephedrine was also calculated in relation to the dry weight of cultures for each treatment.

\section{Extraction and determination of ephedrine concentration}

Ephedrine was extracted from $0.5 \mathrm{~g}$ dry powdered samples of callus and tissue of $E$. alata in $5.0 \mathrm{ml}$ ethanol (HPLC grade) by grinding and then filtration with Whatman No. 1 filter paper. Acidic substances were removed from the filtrate by the application of aliquots of plant extracts to Accell Plus QMA Sep-Pak cartridges (Waters) after dilution with an equal volume of water. Ephedrine level in the aqueous eluent was determined by HPLC (Agilent 1100 series) coupled with the UV-Vis detector G1322A and G1315B DEGASSER by using a method by Barkan et al. (1981). Samples were chromatographed on a ZORBAX-EclipseXDB- ${ }_{18}$ column $(4.6 \times 250 \mathrm{~mm}$, particle size $5 \mu \mathrm{m}$ ) using $1 \%$ acetonitrile in $0.05 \mathrm{~mol}$ monobasic sodium phosphate at $1.0 \mathrm{ml} \cdot \mathrm{min}^{-1}$. Substances in the peaks detected at $210 \mathrm{~nm}$ were identified by comparison of retention times and UV spectra with those of authentic compounds.

\section{Experimental design and statistical analysis}

Experiments were subjected to a completely randomized design with at least three replicates per treatment. Variance analysis of data was carried out using ANOVA program for statistical analysis. The differences among mean values for treatments were tested for signi- 
ficance at $5 \%$ level by using Duncan's multiple range test (Duncan, 1955) as modified by Snedecor and Cochran (1990).

\section{Results and discussion}

The present study was performed to investigate the effect of elicitor concentration and duration of exposure for optimizing ephedrine production and accumulation in suspension culture of $E$. alata. Callus was successfully inducted and proliferated from stem internodal segments of E. alata on MS medium supplemented with $4.52 \mu \mathrm{M}$ of 2,4-D and $4.6 \mu \mathrm{M}$ of $\mathrm{Kn}$ and used as a material for the suspension culture experiment (Fig. 1A). These two plant growth regulators (PGRs) at the same concentration yielded callus in a previous study on callus induction and ephedrine production from $E$. alata (Hegazi and El-Lamey, 2011). Both PGRs were also used at different concentrations for callus induction from Ephedra foliata (Lodha et al., 2014). Callus induction is necessary as the first step for the initiation of suspension cultures for the production of active constituents in tissue culture experiments (Bhatia, 2015). It has been shown that the induction of secondary metabolite production is more effective in the stationary growth phase. Hence, it is necessary to establish a two-stage culture, in which callus biomass is first established in an optimal medium for biomass formation, and cell suspensions are then derived from the callus when transferred to an optimal production medium that stimulates the synthesis of secondary compounds (Ramirez-Estrada et al., 2016). Suspension culture system is used for large-scale culturing of plant cells from which secondary metabolites can be produced and accumulated in large amounts. The advantage of this method is that it can ultimately provide a continuous, reliable source of natural products, thus avoiding the limited availability and complexity of chemical synthesis or extraction from whole plants. Suspension culture has been effectively utilized commercially for the production of valuable secondary metabolites such as taxol, resveratrol, naphtodianthrones, total phenolics, flavonoids, anthocyanins, artemisinin, ginsenosides, and ajmalicine (Xu et al., 2011; Gadzovska et al., 2015; Gonçalves and Romano, 2018). In recent years, suspension culture is viewed as an alternative to traditional agriculture for the industrial production of plant secondary metabolites (Yue et al., 2014).

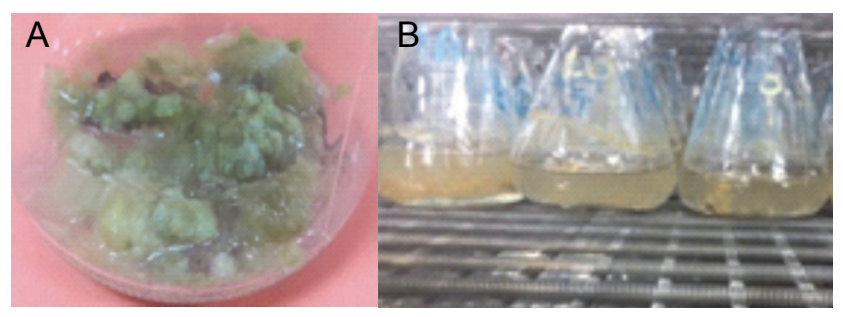

Fig. 1. A) Callus of Ephedra alata induced from internodal segment explants and B) established shake-flask suspension cultures

Aspergillus niger and yeast extracts were chosen in this study for their positive effect on secondary metabolite production as reported in many studies. Mendhulkar and Vakil (2013) reported a significant increase of flavonoid accumulation in suspension cultures of Andrographis paniculata after elicitation with an $A$. niger extract. Aspergillus niger extract also increased the synthesis of psoralen in cell cultures of Psoralea corylifolia (Ahmed and Baig, 2014). Gadzovska et al. (2015) reported a significant increase in naphtodianthrones, total phenolics, flavonoids, and anthocyanins in Hypericum perforatum cell suspensions by adding $A$. niger extract. Yeast extract application improved the production of stilbenes in Cayratia trifolia (Roat and Ramawat, 2009). Yeast extract also effectively enhanced the production of isoflavones and noradrenaline in in vitro cultures of Pueraria candolleiand Portulaca oleracea, respectively (Udomsuk et al., 2011; Pirian and Piri, 2013). Recently, yeast extract was proved to enhance secoisolariciresinol diglucoside, lariciresinol diglucoside, and dehydrodiconiferyl alcohol glucoside biosynthesis in Linum usitatissimum cell cultures (Nadeem et al., 2018).

The effect of elicitation with the two biotic elicitors at different concentrations in suspension cultures of $E$. alata on callus fresh weight and ephedrine production was investigated as shown in Table 1 and Figure 1B. On the basis of the results, no linear correlation was observed between callus weight and different concentrations of the tested elicitors and durations of exposure. For each treatment, an increase in the duration of exposure increased the fresh weight of callus. Aspergillus niger extract at $3.33 \%$ and $5 \%$ concentrations and yeast extract at $15 \%$ concentration increased the fresh weight of callus after some exposure time, but nonsignificantly. However, a large variation was observed in the accumulation of ephedrine in the suspension culture in response to the tested elicitors. 
Table 1. Effect of different concentrations of Aspergillus niger and yeast extract on the callus weight and accumulation of ephedrine in callus cultures of Ephedra alata on MS medium supplemented with $4.52 \mu \mathrm{M}$ of $2,4-\mathrm{D}$ and $4.6 \mu \mathrm{M}$ of Kn

\begin{tabular}{|c|c|c|c|c|}
\hline $\begin{array}{c}\text { Elicitor } \\
\text { concentration } \\
{[\%]}\end{array}$ & $\begin{array}{l}\text { Time } \\
\text { [days] }\end{array}$ & $\begin{array}{c}\text { Fresh weight } \\
{[\mathrm{g}]}\end{array}$ & $\begin{array}{c}\text { Concentration } \\
\text { of ephedrine } \\
{[\%]}\end{array}$ & $\begin{array}{l}\text { Yield of ephedrine } \\
\text { (conc. } \times \text { dry wt.) }\end{array}$ \\
\hline \multirow{5}{*}{$\begin{array}{l}\text { Control } \\
0.0\end{array}$} & 0 & $3.000^{d}$ & 1.529 & 1.070 \\
\hline & 6 & $3.597^{\mathrm{c}}$ & 2.377 & 1.851 \\
\hline & 12 & $3.763^{b c}$ & 2.762 & 2.362 \\
\hline & 18 & $3.889^{b c}$ & 1.344 & 1.037 \\
\hline & 24 & $4.487^{\mathrm{abc}}$ & 3.244 & 2.748 \\
\hline \multirow{4}{*}{$\begin{array}{l}\text { A. niger extract } \\
1.67\end{array}$} & 6 & $3.938^{\mathrm{bc}}$ & 1.772 & 1.498 \\
\hline & 12 & $4.424^{\mathrm{abc}}$ & 3.091 & 2.695 \\
\hline & 18 & $4.470^{\mathrm{abc}}$ & 2.396 & 2.226 \\
\hline & 24 & $4.707^{\mathrm{abc}}$ & 3.533 & 3.271 \\
\hline \multirow{4}{*}{$\begin{array}{l}\text { A. niger extract } \\
3.33\end{array}$} & 6 & $4.038^{\mathrm{abc}}$ & 1.901 & 1.601 \\
\hline & 12 & $4.858^{\mathrm{abc}}$ & 2.476 & 1.877 \\
\hline & 18 & $5.432^{\mathrm{abc}}$ & 2.170 & 2.026 \\
\hline & 24 & $5.450^{\mathrm{abc}}$ & 1.979 & 1.775 \\
\hline \multirow{4}{*}{$\begin{array}{l}\text { A. niger extract } \\
\quad 5.00\end{array}$} & 6 & $3.621^{\mathrm{c}}$ & 2.287 & 1.946 \\
\hline & 12 & $3.726^{\mathrm{bc}}$ & 2.137 & 1.735 \\
\hline & 18 & $4.367^{\mathrm{abc}}$ & 1.903 & 1.633 \\
\hline & 24 & $6.008^{\mathrm{ab}}$ & 2.268 & 2.322 \\
\hline \multirow{4}{*}{$\begin{array}{l}\text { Yeast extract } \\
\quad 5\end{array}$} & 6 & $3.903^{b c}$ & 1.827 & 1.476 \\
\hline & 12 & $4.247^{\mathrm{abc}}$ & 1.593 & 1.423 \\
\hline & 18 & $5.191^{\mathrm{abc}}$ & 1.685 & 1.545 \\
\hline & 24 & $5.279^{\mathrm{abc}}$ & 1.747 & 1.581 \\
\hline \multirow{4}{*}{$\begin{array}{l}\text { Yeast extract } \\
\quad 10\end{array}$} & 6 & $3.429^{c}$ & 1.577 & 1.244 \\
\hline & 12 & $3.612^{c}$ & 2.093 & 1.298 \\
\hline & 18 & $3.862^{b c}$ & 1.290 & 1.057 \\
\hline & 24 & $4.371^{\mathrm{abc}}$ & 1.081 & 0.927 \\
\hline \multirow{4}{*}{$\begin{array}{l}\text { Yeast extract } \\
\quad 15\end{array}$} & 6 & $4.194^{\mathrm{abc}}$ & 2.174 & 1.761 \\
\hline & 12 & $5.446^{\mathrm{abc}}$ & 1.247 & 1.060 \\
\hline & 18 & $5.984^{\mathrm{ab}}$ & 1.803 & 1.577 \\
\hline & 24 & $6.270^{\mathrm{a}}$ & 2.375 & 2.589 \\
\hline Mother plant & & & 0.505 & \\
\hline
\end{tabular}

Values followed by the same superscripted letter in a column are not significantly different $(P>0.05)$, according to Duncan's multiple range test

The production of ephedrine varied according to the two tested elicitors. Regarding the concentration of ephedrine and its yield, the highest content of ephedrine of $3.533 \%$ in terms of yield of $3.271 \mathrm{mg}$ in total dry wt. was obtained after 24 days in $E$. alata suspension cultures treated with $1.67 \%$ of $A$. niger extract. The control treatment without elicitors was at the second spot, with ephedrine content of $3.244 \%$ in terms of yield of $2.748 \mathrm{mg}$ in total dry wt. The $A$. niger extract concentration of $3.33 \%$ yielded highest ephedrine content of $2.476 \%$ after 12 days of exposure, which decreased by decreasing or increasing exposure time. The addition of 
5\% A. niger extract showed the highest ephedrine accumulation only after 6 days and then decreased after prolonged exposure.

Regarding the effect of yeast extract on ephedrine accumulation, the data showed that the highest accumulation of ephedrine was recorded at the concentration of $15 \%$ after 24 days of exposure, reaching the value of $2.375 \%$ in terms of yield of $2.589 \mathrm{mg}$ in total dry wt. However, yeast extract at $10 \%$ concentration showed the highest accumulation of ephedrine only after 12 days of exposure (2.093\%), which decreased with increasing time and reached values lower than the control treatment (1.290\% and $1.081 \%$ after 18 and 24 days, respectively). The addition of $5 \%$ yeast extract gave the highest ephedrine accumulation only after 6 days (1.827\%), which then decreased after prolonged exposure.

Figure 2 illustrates the effect of different concentrations of the tested elicitors on ephedrine content for different treatment durations in suspension cultures of $E$. alata (by folds) in comparison to its content in the mother plant. Among the different treatments, the production of ephedrine was stimulated by the $A$. niger extract at the concentration of $1.67 \%$ up to 7 -fold within 24 days as compared to the ephedrine content in the mother plant, followed by the control treatment without elicitation after 24 days of exposure by 6.427 -fold. For yeast extract at $15 \%$ concentration, ephedrine concentration was increased up to 4.707 -fold within 24 days of culture as compared to the ephedrine content in the mother plant. In general, for the best treatment, the results obtained reveal that the longer treatment duration is most favorable for the production of ephedrine using both biotic elicitors. Similar results were obtained by Vakil and Mendhulkar (2013), who found that the elicitation treatment with the fungal elicitors $A$. niger extract was observed to be most suitable for eliciting andrographolide production in the cell suspension culture of Andrographis paniculata and enhanced its accumulation by 6.94 -fold.

The results of the present study illustrate the success in increasing ephedrine content in $E$. alata suspension culture even in the control medium as compared to that obtained in the previous study of Hegazi and ElLamey (2011), who obtained a maximum ephedrine content of $1.406 \%$ of dry weight of callus cultured on the same control medium, but in the solid state. The authors found that feeding the culture medium with different concentrations of L-phenylalanine as a precursor or ca-

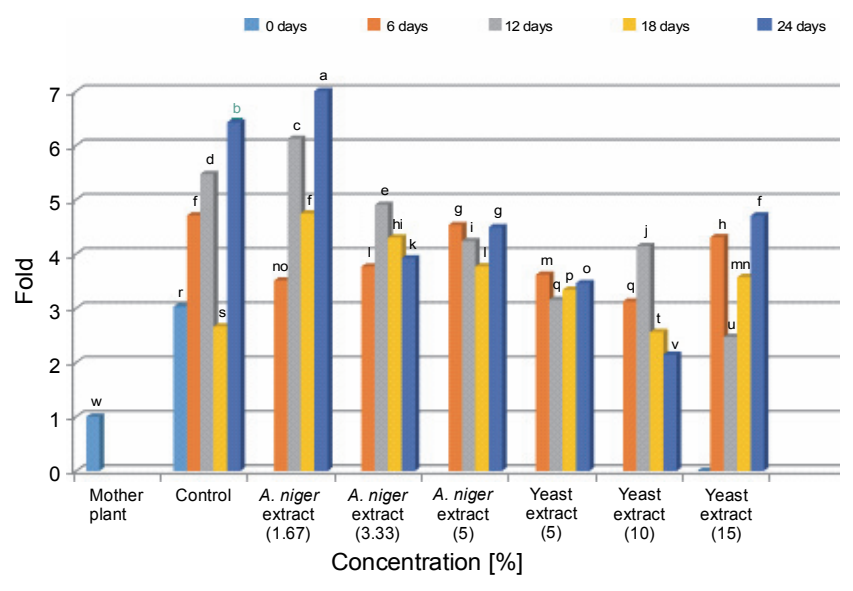

Fig. 2. Comparison of ephedrine content (in fold) between the mother plant and different elicitor treatments (Aspergillus niger and yeast extract) and durations of Ephedra alata suspension culture; values followed by the same superscripted letter are not significantly different $(P>0.05)$, according to

Duncan's multiple range test

sein hydrolysate as an elicitor did not increase ephedrine accumulation.

Plant cells interact with elicitors at the metabolic level. After treatment with elicitors, defense responses are induced in plants, including the accumulation of various secondary metabolites, at high levels. Mendhulkar and Vakil (2013) hypothesized the elicitation mechanism as the binding of the elicitor to plasma membrane receptors, which initiates signaling processes that activate plant defense. Fungal elicitors have been widely used to increase the accumulation of natural products in plant cell cultures, and this strategy has been effective in stimulating the production of many chemical classes of secondary metabolites such as alkaloids (Taha et al., 2009), phenolics, flavonoids, anthocyanins (Mendhulkar and Vakil, 2013; Gadzovska et al., 2015), and glucosides (Nadeem et al., 2018). In the present study, the $A$. niger extract was found to be useful for the enhancement of ephedrine accumulation. It was observed that treatment with the lowest concentration of $A$. niger extract caused the highest elicitation; thus, elicitor concentration and the exposure time are very critical for the elicitation of ephedrine production. This result agrees with that reported by Taha et al. (2009), who found that $0.25 \%$ of $A$. niger extract resulted in the production and accumulation of the highest amount of total alkaloids, vinblastine, and vincristine in the callus culture of Catharanthus roseus. Mendhulkar and Vakil (2013) also reported 
a significant increase in flavonoid accumulation in suspension cultures of Andrographis paniculata after elicitation with an $A$. niger extract. Moreover, Gadzovska et al. (2015) observed a significant increase in naphtodianthrones, total phenolics, flavonoids, and anthocyanins in $\mathrm{Hy}_{-}$ pericum perforatum cell suspensions treated with $A$. $n i$ ger extract. However, as reported in the present study, increasing the concentration of $A$. niger extract showed less ephedrine accumulation. This may be because the mycotoxins have hindered ephedrine production and its biosynthetic pathway was negatively affected. Similar results were reported by Mathur (2018), who found a considerable decrease in secondary metabolite production and growth of Commiphora wightii, Zingiber officinale, and Daucus carota cell suspension cultures when $A$. niger extract was used as an elicitor.

The positive effect of yeast extract on the accumulation of ephedrine is consistent with the results of other authors such as Udomsuk et al. (2011) and Pirian and Piri (2013), who found that yeast extract was the most effective elicitor for the production of isoflavones and noradrenaline in cultures of Pueraria candollei and Portulaca oleracea, respectively. Nadeem et al. (2018) also reported enhanced biosynthesis of secoisolariciresinol diglucoside, lariciresinol diglucoside, and dehydrodiconiferyl alcohol glucoside in Linum usitatissimum cell cultures, when yeast extract was used as an elicitor. It is assumed that the effect of yeast extract as an elicitor may be associated with the presence of some cations in it, such as $\mathrm{Zn}, \mathrm{Ca}$, and $\mathrm{Co}$, which act as abiotic elicitors (Srivastava and Srivastava, 2014). On the other hand, the presence of amino acids, vitamins, and minerals in the yeast extract complex may play a role in the regulation of enzyme activity in the pathway of ephedrine biosynthesis (Srivastava and Srivastava, 2014).

From the results, it is apparent that in many instances, the amount of ephedrine in the control treatment was higher than that when using elicitors. This was especially observed for yeast extract at $10 \%$ and $15 \%$ concentrations; this finding may be attributed to the consideration that some elicitor concentrations and durations of exposure could be sub- or supra-optimum to achieve high ephedrine production as compared to that obtained in the control treatment. Moreover, other factors such as culture conditions and environmental and physical factors (light, $\mathrm{pH}$, temperature, shaking speed, etc.) need to be optimized to achieve a high production
(Cusido et al., 2014; Ramirez-Estrada et al., 2016). Furthermore, a suitable elicitor and its concentration are important for cell growth and product yield in the plant suspension culture process. Optimum use of elicitors depends on different factors such as elicitor specificity, its concentration, time and duration of exposure, culture growth stage, growth regulation, and nutrient composition. Because of such high specificities of actions, the failure of one elicitor does not necessarily mean that the metabolic pathway cannot be triggered, thus indicating that a large number of elicitors need to be screened for accomplishing effective elicitation process (Patel and Krishnamurthy, 2013). Gonçalves and Romano (2018) reported that the incomplete knowledge of the metabolic pathways of the biologically active compounds limits the success of scaling up their production. The authors emphasized that modern molecular biology techniques are needed to enhance the production of secondary metabolites by engineering their biosynthetic pathways in plant tissues, in addition to the use of new promising elicitors.

In general, the accumulation of ephedrine was promising and varied largely according to the applied elicitors. Ephedrine accumulated in huge amounts as compared to that in the mother plant (7-fold) and the control treatment without elicitation after 24 days of exposure (6.427-fold). These results are very promising for the large-scale production of this valuable bioactive compound. The present investigation could be scaled up for the production of commercially feasible levels of ephedrine by using suspension cultures of $E$. alata.

\section{Acknowledgments}

The authors are thankful to Dr. Amira Yahia, Lecturer of Microbiology, Botany and Microbiology Department, Faculty of Science (Girls branch), Al-Azhar University, for providing the fungal strain of Aspergillus niger.

\section{References}

Ahmad S., Garg M., Tamboli E.T., Abdin M.Z., Ansari S.H. (2013) In vitro production of alkaloids: factors, approaches, challenges and prospects. Pharmacogn. Rev. 7: 27-33.

Ahmed S.A., Baig M.M.V. (2014) Biotic elicitor enhanced production of psoralen in suspension cultures of Psoralea corylifolia L. Saudi J. Biol. Sci. 21: 499-504. DOI: http:// doi.org/10.1016/j.sjbs.2013.12.008.

Al-khateeb E., Al-Ani H., Al-Kadi K., Al-Obaidi E.D.F., Shalan N., Al-Rawi N. (2014) Investigation of the alkaloids of two Ephedra Spp. wildly grown in Iraq. Jordan J. Pharm. Sci. 7(3): 191-198. 
Al-Snafi A.E. (2017) Therapeutic importance of Ephedra alata and Ephedra foliate - a review. Indo Amer. J. Pharm. Sci. 4(2): 399-406.

Barkan S., Weber J.D., Smith E. (1981) Determination of crosscontamination of the diastereomers ephedrine and pseudoephedrine by high-performance liquid chromatography, thinlayer chromatography and carbon-13 nuclear magnetic resonance spectroscopy. J. Chromatogr. 219: 81-88.

Bhatia S. (2015) Plant tissue culture. [in:] Modern applications of plant biotechnology in pharmaceutical sciences. ScienceDirect: 31-107.

Boulos L. (2009) Flora of Egypt cheklist. Revised Annonated Edition, Alhadara Publishing, Egypt.

Chebouat E., Dadamoussa B., Gharabli S., Gherraf N., Allaoui M., Cheriti A., Lahham A., Zellagui A. (2014) Assessment of antimicrobial activity of flavonoids extract from Ephedra alata. Der Pharmacia Lett. 6(3): 27-30.

Duncan D.B. (1955) Multiple range and multiple " $F$ " test. Biometrics 11: 1-42.

Gadzovska S.S., Tusevski O., Maury S., Hano C., Delaunay A., Chabbert B., Lamblin F., Lainé E., Joseph C., Hagège D. (2015) Fungal elicitor-mediated enhancement in phenylpropanoid and naphtodianthrone contents of Hypericum perforatum L. cell cultures. Plant Cell Tissue Organ. Cult. 122: 213-226. DOI: http://doi.org/10.1007/s11240-0150762-y.

Gonçalves S., Romano A. (2018) Production of plant secondary metabolites by using biotechnological tools. Secondary metabolites - sources and applications. IntechOpen, Web of Science. DOI: http://doi.org/10.5772/ intechopen. 76414.

Hegazi G.A., El-Lamey T.M. (2011) Callus induction and extraction of ephedrine from Ephedra alata Decne. cultures. Amer.-Eurasian J. Agr. Environ. Sci. 11(1): 19-25.

Jaradat N., Hussen F., Al-Ali A. (2015) Preliminary phytochemical screening, quantitative estimation of total flavonoids, total phenols and antioxidant activity of Ephedra alata Decne. J. Mater. Environ. Sci. 6(6): 1771-1778.

Khan A., Jan G., Khan A., Jan F.G., Bahadur A., Danish M. (2017) In vitro antioxidant and antimicrobial activities of Ephedra gerardiana (root and stem) crude extract and fractions. Evidence-based Complementary and Alternative Medicine, Article ID 4040254.

Limberger R.P., Jacques A.L.B., Schmitt G.C., Arbo M.D. (2013) Pharmacological effects of Ephedrine. [in:] Natural Products. Ed. Ramawat K.G., Merillon J.M. SpringerVerlag, Berlin, Heidelberg: 1218-1233. DOI: http:// doi.org/10.1007/978-3-642-22144-6_41.

Lodha D., Patel A.K., Rai M.K., Shekhawat N.S. (2014) In vitro plantlet regeneration and assessment of alkaloid contents from callus cultures of Ephedra foliata (Unth phog), a source of anti-asthmatic drugs. Acta Physiol. Plant. 36(11): 3071-3079.

Mathur M. (2018) Effect of fungal elicitation on growth and metabolite production in callus of few medicinal plants. Inter. J. Life Sci. A9: 114-116.
Mendhulkar V.D., Vakil M.M.A. (2013) Elicitation of flavonoids by salicylic acid and Penicillium expansum in Andrographis paniculata (Burm.f.) Nees. Cell Cult. Res. Biotech. 4(2): 1-9.

Murashige T., Skoog F. (1962) A revised medium for rapid growth and bioassays with tobacco tissue cultures. Physiol. Plant. 15: 473-497.

Narayani M., Srivastava S. (2017) A stimulation of stress in in vitro plant cell/tissue cultures for enhancement of secondary metabolite production. Phytochem. Rev. DOI: http:// doi.org/10.1007/s11101-017-9534-0.

Nadeem M., Abbasi B.H., Garros L., Drouet S., Zahir A., Ahmad W., Giglioli-Guivarch N.G., Hano C. (2018) Yeast-extract improved biosynthesis of lignans and neolignans in cell suspension cultures of Linum usitatissimum L. Plant Cell Tiss. Org. 135(2): 347-355.

Patel H., Krishnamurthy R. (2013) Elicitors in plant tissue culture. J. Pharmacogn. Phytochem. 2(2): 60-65.

Parsaeimehr A., Sargsyan E., Javidnia K. (2010) A comparative study of the antibacterial, antifungal and antioxidant activity and total content of phenolic compounds of cell cultures and wild plants of three endemic species of Ephedra. Molecules 15(3): 1668-1678.

Peltonen S., Mannonem L., Karjalainem R. (1997) Elicitorinduced changes of phenylalanine ammonia-lyase activity in barley cell suspension cultures. Plant Cell Tiss. Org. 50: 185-193.

Pirian K., Piri K. (2013) Influence of yeast extract as a biotic elicitor on noradrenaline production in hairy root culture of Portulaca oleracea L. Int. J. Agron. Plant Prod. 4: 2960-2964.

Ramirez-Estrada K., Vidal-Limon H., Hidalgo D., Moyano E., Goleniowski M., Cusidó R.M., Palazon J. (2016) Elicitation, an effective strategy for the biotechnological production of bioactive high-added value compounds in plant cell factories. Molecules 21(2): 182. DOI: http://doi.org/ 10.3390/molecules21020182.

Roat C., Ramawat K.G. (2009) Elicitor-induced accumulation of stilbenes in cell suspension cultures of Cayratia trifolia (L.) Domin. Plant Biotechnol. Rep. 3: 135-138. DOI: http://doi.org/10.1007/s11816-009-0082-y.

Schluttenhofer C., Yuan L. (2015) Regulation of specialized metabolism by WRKY transcription factors. Plant Physiol. 167: 295-306.

Shakya P., Marslinb G., Siramc K., Beerhuesd L., Franklina G. (2017) Elicitation as a tool to improve the profiles of high value secondary metabolites and pharmacological properties of Hypericum perforatum. J. Pharm. Pharmacol. 71(1): 70-82.

Snedecor G.W., Cochran W.G. (1990) Statistical methods. Ed 8. Iowa State University Press, Ames, Iowa, USA.

Soltan M.M., Zaki A.K. (2009) Antiviral screening of forty-two Egyptian medical plants. J. Ethnopharmacol. 126(1): 102-107.

Srivastava S., Srivastava A.K. (2014) Effect of elicitors and precursors on azadirachtin production in hairy root culture 
of Azadirachta indica. Appl. Biochem. Biotechnol. 172: 2286-2297.

Taha H.S., El-Bahr M.K., Seif-El-Nasr M.M. (2009) In vitro studies on Egyptian Catharanthus roseus (L.). II. Effect of biotic and abiotic stress on indole alkaloids production. J. Appl. Sci. Res. 5: 1826-1831.

Udomsuk L., Jarukamjorn K., Tanaka H., Putalun W. (2011) Improved isoflavonoid production in Pueraria candollei hairy root cultures using elicitation. Biotechnol. Lett. 33: 369-374.

Vakil M.A., Mendhulkar V.D. (2013) Enhanced synthesis of andrographolide by Aspergillus niger and Penicillium expansum elicitors in cell suspension culture of Andrographis paniculata (Burm. f.) Nees. Bot. Stud. 54: 49.

Verma V., Ravindran P., Kumar P.P. (2016) Plant hormonemediated regulation of stress responses. BMC Plant Biol. 16: 86 .
Yue W., Ming L.Q., Lin B., Rahman K., Zheng J.C., Han T., Qin L. (2014) Medicinal plant cell suspension cultures: Pharmaceutical applications and high-yielding strategies for the desired secondary metabolites. Crit. Rev. Biotechnol. 36(2): 1-18.

Yue W., Ming L.Q., Lin B., Rahman K., Zheng J.C., Ting Han T., Qin L. (2016) Medicinal plant cell suspension cultures: pharmaceutical applications and high-yielding strategies for the desired secondary metabolites. Crit. Rev. Biotechnol. 36(2): 215-232.

Xu J., Ge X., Dolan M.C. (2011) Towards high-yield production of pharmaceutical proteins with plant cell suspension cultures. Biotechnol. Adv. 29: 278-299. 